증 례

$$
\begin{gathered}
\text { 급성 호흡부전을 일으킨 상부기관 및 후두 결핵 } \\
\text { 서울대학교 의과대학 내과학교실 결핵연구소 } \\
\text { 유 철 규・정 만 표・한 성 구 } \\
\text { 심 영 수·김 건 열・한 용 철 } \\
\text { 이비인후과학 교실 }
\end{gathered}
$$$$
\text { 김 광 현 }
$$

$=\mathbf{A b s t r a c t}=$

\title{
A Case of Proximal Tracheal and Laryngeal Tuberculosis Causing Acute Respiratory Failure
}

\author{
Chul Gyu Yoo, M.D., Man Pyo Jung, M.D., Sung Koo Han, M.D. \\ Young Soo Shim, M.D., Keun Youl Kim, M.D. and Yong Chol Han, M.D. \\ Department of Internal Medicine, College of Medicine, Tuberculosis Research \\ Institute, Seoul National University \\ Kwang Hyun Kim, M.D. \\ Department of Otolaryngology
}

\begin{abstract}
Since endobronchial tuberculosis was first described in 1689, it remained infrequently reported until the era of bronchoscopy in 1930s and 1940s. However, tracheal involvement was rare then and remains so today. Tuberculous tracheobronchitis and laryngitis is probably almost always secondary to active pulmonary tuberculosis.

Tuberculous tracheitis may be ulcerative or infiltrative at the inflammatory stage. A stenosis at this stage is due to inflammatory swelling, whereas in the healing phase it is mainly due to fibrosis. So it is a troublesome therapeutic problem due to its sequelae, i.e., cicatrical stenosis.

Most of the tuberculous tracheitis are present just above the carina, and development of distal tracheal stenosis during treatment of tuberculosis has been recorded. It is thought to be related to the pathogenesis of tracheal tubeculosis, i.e., proximal extension of endobronchial tuberculosis with AFB-laden sputum. But proximal tracheal swelling with stridor which requires emergency tracheostomy cannot he found in literature except one case report.

We report a case of proximal tracheal and laryngeal tuberculosis causing acute respiratory failure, which required emergency tracheostomy.
\end{abstract}

서 론

후두의 결핵은 잘 알려진 질환이며 항결핵화학요법이 개발되기 전에는 가장 흔한 후두의 질환중 하나였으남), 1940 년대말 SM과 1950년대초 $\mathrm{INH}$ 의 개발이후 발병율 이 점차 감소되어 가고 있는 추세로 최근에는 드물게 보
는 질환중의 하나이다.

폐결핵에 동반되어 발생하는 기관기관지 결핵도 잘 알 려져 있고, 치료후 합병증인 하부 기도협착에 대해서도 많이 보고되어 있다. 그러나 이때 발생하는 기도협착은 거의 대부분이 하부기관지에 발생하며 드물게 기관 자체 를 침범하더라도 거의 대부분은 기관 결핵의 발병기전상 기관분기부 주위의 하부 기관을 침범한다. 이에 따라 하 
부 기관 협착에 의한 천명과 기관지 천식을 감별하는 것 은 임상에서 종종 문제가 되고 있다.

그러나 결핵이 상부기관(proximal trachea)를 침범 하여 천명 (stridor)을 일으키고 급성 호흡부전을 야기한 경우는 저자들이 찾은 바로는 1987년의 1예2)를 제외하 고는 거의 문헌 보고가 없는 상태이다.

저자들은 최근 서울대학교 병원에 중증의 호흡곤란을 주소로 입원한 19세 여자 환자에서 상부기관 및 후두 결 핵으로 급성 호흡부전이 생겨 응급 기관절개술을 요했던 예를 경험하였기에 문헌 고찰과 함께 보고하는 바이다.

\section{증 례}

환 자: 정 신, 19 세, 여자.

주 소: 심한 호흡곤란.

병 력 : 과거력상 특이!ㅎ항 없었으며, 입원 수개월전 부터 주로 오후에 발생하는 미열, 피로감, 기침 및 발한 등의 증상이 있어 왔으나 일상생활에 큰 지장을 받을 정 도는 아니어서 의료기관을 찾지않고 지내왔다. 입원 약 2 개월전부터 사성이 나타나고 입원 10 일전부터 호흡곤란 이 나타나기 시작하였다. 입원 3 일전 개인병원에서 단순 훙부 방사선 검사 시행후 폐결핵이라 진단받고 항결핵화 학요법을 받기 시작하였다. 입원 2 일전부터 호흡곤란이
심해져 입원당일 이비인후과 의원 방문한 후 본원 응급 실로 전원되었다.

가족력 : 특이사항 없음.

사회력 : 흡연력-없음.

직업력 : 전문대학 1 학년 재학중.

이학적 소견: 입원당시 생체징후상 혈압은 $130 / 90$ $\mathrm{mmHg}$, 맥박수는 분당 98 회, 호흡수는 분당 30 회, 체 온은 $37.8^{\circ} \mathrm{C}$ 였고 의식은 명료하였으며 지남력도 보존되 었다. 안면, 경부, 심장, 복부 및 신경학적검진상 특기 할 만한 이상 소견은 없었으며 흥부 검진상 흡기시 심한 흥벽의 퇴축(retraction)이 있었고 청진상 호흡음은 명 확하였으나 심한 천명 (stridor)이 들렸고 심한 도한과 함 께 청색증이 관찰되었다.

검사소견 : 혈액검사상 혈색소친는 $13.5 \mathrm{~g} / \mathrm{dl}$, 백혈구 수는 $6200 / \mathrm{mm}^{3}$, 혈소판수는 $368,000 / \mathrm{mm}^{3}$, 적혈구 침 강속도는 $36 \mathrm{~mm} / \mathrm{hour}$ 였으며 출혈 성 경향은 없었다. 혈 청학적으로 매독 반응이나 $\mathrm{B}$ 형 간염항원은 음성이었고 혈액화학검사, 간기능검사 및 심전도, 그리고 소변 및 대변검사도 모두 정상이었다. 객담 항산균 검사는 $3(+)$ 였다. 간접후두경으로 육안적 관찰시 후두의 내측점막이 괴사성 물질로 덮여 있었고 성문 주위의 심한 협착이 발 견되였다. 응급실에서 응급기관절개술을 시행하며 기도 와 그 주위 임파선 조직의 생검을 시행하였는데 병리학
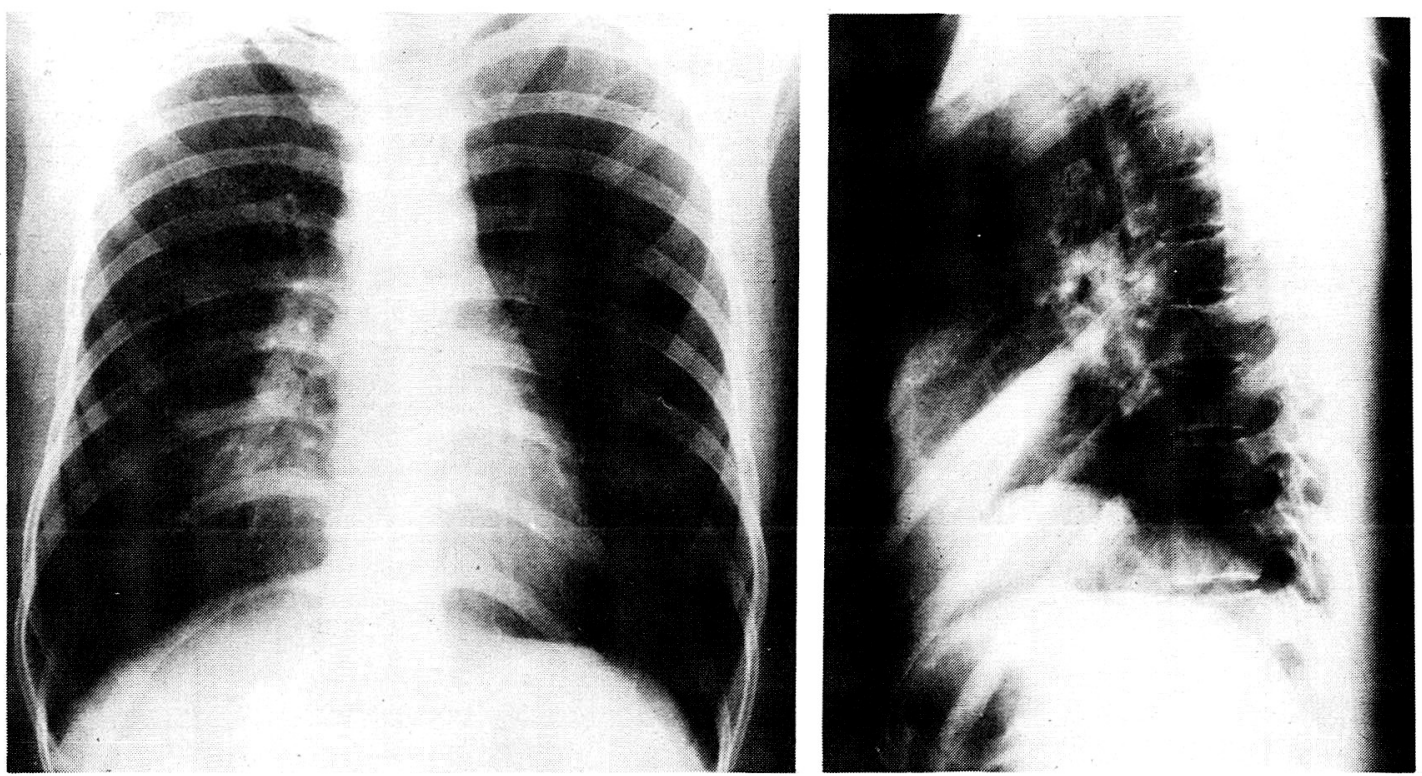

Fig. 1. Chest PA and lateral view showing ground glass appearanced haziness obliterating right cardiac border and triangular shaped homogeneous haziness in right lateral film. 
적 소견상 모든 표본에서 결핵에 합당한 소견인 만성 육 아종성 염증을 보이고 있었다.

방사선 소견 : 단순 흉부방사선 검사상 우측 심장경계 에 연하여 간유리모양의 증가된 음영 (ground glass appearanced haziness) 을 보였고 단순 우측면 흥부방사 선 검사상 삼각형모양의 균질의 음영 증가가 관찰되어 우 중엽 허탈의 소견을 보이고 있었다(Fig. 1).

경 과 : 환자는 응급실에서 후두질환에 의한 상기도 폐쇄로 생각되어 기도 유지를 위한 응급기관절개술을 시 행받은 후 호흡곤란 및 청색증이 소실되었다. 입원하여 각종 검사후 후두 및 상부기관 결핵으로 진단되어 항결 핵 제 (SM, INH, RFP, PZA) 와 prednisolon $40 \mathrm{mg}$ 을 2 번에 나눠서 (30-10 mg) 복용하기 시작하였으며 항결핵 제와 스테로이드제재를 사용한지 2주후 기관지 내시경 검 사를 시행하였다. 이때 성대는 정상이었고 상부 기도 점 막은 충혈되어 있었으며 구경의 협착과 함께 전체적인 부 종의 소견을 보이고 있였다. 우측 주기관지는 전체적으 로 약간 좁아져 있었으며 우중엽 기관지는 심한 염증에 의한 중증의 협착을 보이고 있었다(Fig. 2). 입원 16 일 째에 기관절개관을 제거한 후 별 문제없이 퇴원하였다. 퇴원후 환자는 정기적인 외래통원 치료를 받으며 스테로 이드를 점차적으로 줄여 나가던 중 3개월만에 다시 경증 의 호흡곤란이 나타나고 청진상 천명이 들렸다. 퇴원 4 개월후에 다시 기관지 내시경검사를 시행하였다. 성대에
서 기도 중간부위까지는 직경 $5.9 \mathrm{~mm}$ 내시경이 통과할 수 없을정도로 섬유조직증식에 의한 협착이 있었다(Fig. 3). 기도 협착의 정도를 보기위해 기도 단층 찰영술을 시 행하였는데 7 번 경추부위 부터 기관부기부의 상부까지 협 착이 이어져 있었다(Fig. 4). 헙착부위가 너무 길어 절 제가 불가능하다고 판단되어 현재 내과적 치료 하에 외 래통원 치료 및 관찰중이다.

\section{고 안}

1838년 Carswelli3)이 부검예에서 처음으로 보고한 이 래 부검 혹은 임상적으로 증명된 기관 결핵에 대한 여러 보고가 있었다. 기관기관지 및 후두 결핵은 대개 폐결핵 에 수반되어 발생하는 것으로 알려져 있으며, 경증, 중 등증 및 중증의 폐결핵 모두에서 발생 가능한 것으로 알 려져 있단. 1904년 Hansemann 등은 원발성 기관 결 핵을 처음으로 보고하였으며 그 이후의 여러 보고로부터 빈도는 낮지만 기관외에는 결핵병소가 없는 원발성 기관 결핵에 대해서도 잘 알려져 있다. 문헌상에 보고된 부검 예에서 기관기 관지 결핵의 빈도는 $3.1 \%{ }^{5}$ 에서 $72 \%{ }^{6}$ 로 많 은 차이가 있다. 1949년 Auerbach' ${ }^{7}$ 의 1000 명 부검예에 서 기관 또는 기관지를 침범한 예는 421 예로 $42.1 \%$ 였고 기관만을 침범한 예는 92 예로 $9.2 \%$ 였다.

기관 결핵의 발생 연령은 20 30대가 가장 많으며, 남

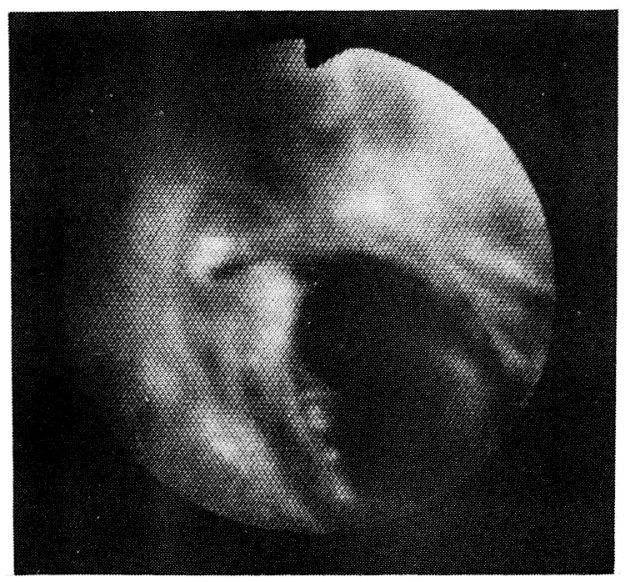

Fig. 2. Bronchoscopy showing inflammation, diffuse edema, and necrotic debris of proximal trachea.

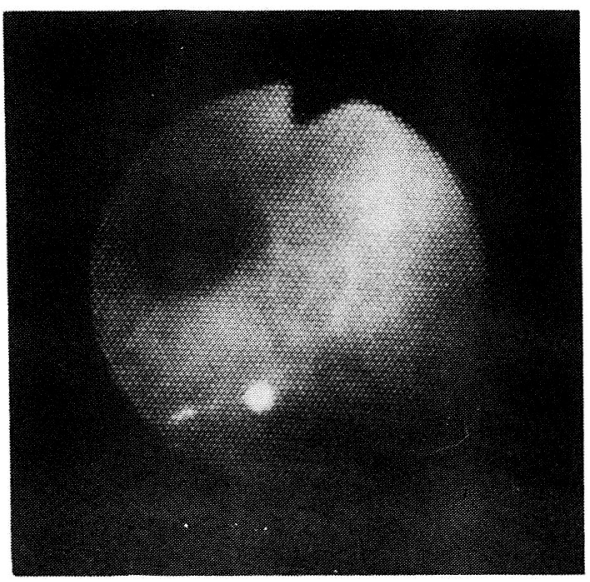

Fig. 3. Follow up bronchoscopy after treatment showing fibrotic stenosis of proximal trachea. 


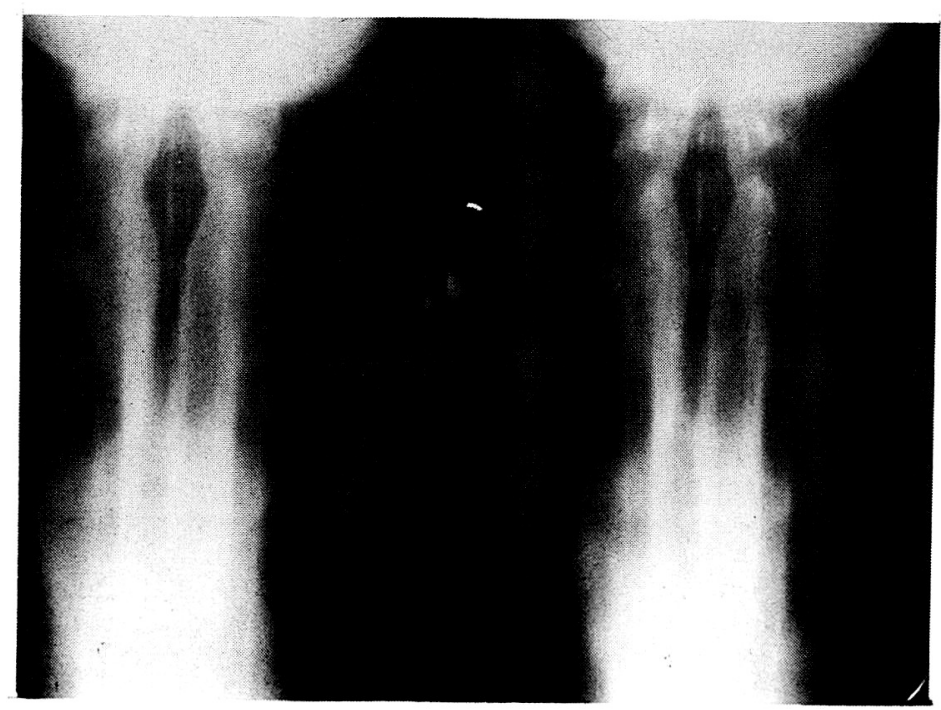

Fig. 4. Tomography of trachea showing tracheal stenosis from $\mathrm{C}_{7}$ level to upper portion of carina.

자보다 여자에서 더 많이 발생 하는 것으로 알려져 있으 나 그 이유는 확실치가 않다 ${ }^{4,7}$. 여자가 남자보다 효과적 으로 객담 객출을 못해 결핵균에 오염된 객담과 기관 및 기관지와의 접촉 시간이 길기 때문인 것으로 생각하고 있 다 ${ }^{4)}$. 반면에 후두 결핵은 남자에서 더 흔히 발견되는데 최근 남녀비는 점점 증가하는 추세이다 ${ }^{8.9)}$. 기관기관지 및 후두 결핵의 병인론에 대해서는 수년간 토론의 쟁점 이 되어 왔으나 대부분의 저자들은 결핵균에 오염된 객 담이 기관 및 기관지점막에 접촉하고 강내로 침범하여 생 기는 것으로 보고하고 있으나 임파성과 혈행성 및 주위 조직으로부터의 직접전파도 가능하리라고 알려져 있 다 ${ }^{3,4,7)}$. 병변은 주로 기관과 후두의 후부 및 후측부에 생 기는 것으로 알려져 있으며 이는 중증 폐결핵 환자의 복 위 (supine) 자세에 기인 한다고 추측된다. 기관 결핵의 대 부분은 기관지의 병변이 기관쪽으로 확장되어 발생하기 때문에 기관 분기부주위에 생기며 상부기관을 침범한 예 에 대한 보고는 거의 없는 상태이다2,8). 그러나 본례처럼 후두 결핵과 동반된 기관결핵의 경우에는 결핵균이 포함 된 분비물이 기관으로 흘러내려 상부 기관 결핵과 동반 되는 기전을 생각해 볼 수 있다. 그러나 이제까지 상부 기관 결핵과 후두 결핵이 동반되어 급성 호흡부전을 일 으킨 예는 1987 년의 1 예2)만 보고되어 있을 뿐이어서 본 예에서 우 중엽기관지에 기관지 결핵이 동반되어 있었던 점은 상부 기관 결핵의 발병기전에 관한 명확한 설명을
어렵게 하고 있다.

기관 결핵의 임상 증상은 폐결핵과 수반되어 있는 경 우가 대부분이므로, 기침, 객담, 발열, 체중감소 등의 폐 결핵에서 흔히 보는 증상이 나타나지만 기관 결핵의 고 유 증상이라고 할 수는 없다. 후두 결핵의 경우는 사성 이 추증상으로 나오는 경우가 많고 그외에 기침, 체중감 소, 인후통, 연하곤란 등이 있을 수 있다9). 기관 및 후 두의 병변이 진행되어 협착이 생긴 경우는 호흡곤란이 나 타나며 이는 폐실질의 병변으로 예측할 수 있는 정도보 다 심하며 간혹 기관 절개술을 요하는 경우도 있다2.10). 훙부 청진상 나음이나 천명음 등이 들릴 수도 있다. 원 발성 기관 결핵은 협착을 일으킬 때 까지 고유 증상이 없 기 때문에 진단이 어렵고 알레르기성 천식이나 천식성 기 관지염으로 오진되는 경우도 흔하닥. 본 예에서 외래 통 원시 발견된 기관의 반흔성 협착은 기관절개술 후에도 가 능하기 때문에 기관절개술의 후유증을 완전히 배제할 수 는 없다.

기관기관지 및 후두 결핵의 경우는 폐결핵때 보다 객 담도말검사상 항상균 양성율이 높고 감염 성도 높은 것으 로 알려져 있으나 ${ }^{11)}$ 감염성을 결 정하는 것은 수반된 폐 결핵의 정도 및 활성도이지 기관 및 후두 결핵 자체는 아 니다. 폐결핵이 치료된 후에도 지속적으로 객담 항산균 이 양성인 경우는 반드시 기관기관지 및 후두 결핵을 의 심해야 한단) 
홍부 방사선 검사에서는 기관지 결핵의 경우 무기폐가 가장 흔한 소견이며 부분적 기관지 폐쇄때는 폐기종으로 나타날 수도 있다4). 그러나 기도 결핵의 경우는 단순 홍 부 방사선 검사에서 이상 소견을 발견하기가 힘들기 때 문에 기관 단층 조영술 등의 특수 검사가 필요하다. 이 상과 같이 기관 결핵에 대한 고유 증상 및 증후가 없기 때문에 기관 결핵의 진단은 기관지 내시경에 의존하게 되 며 후두 결핵 환자의 경우는 간접 또는 직접 후두경 검 사가 필요하다.

결핵 환자에서 기관지 내시경 검사의 금기 사항은 후 두의 궤양성 병변, 최근의 출혈, 말기 폐질환 및 광범위 한 기관 병변등이 있으나 거의 모든 경우에서는 적응증 이 된단). 기관지 내시경에 의한 기관기관지 결핵의 육 안적 분류는 여러가지가 있으나 간단하게 비궤양성, 비 협착성군(nonulcerative, nonstenotic), 증식성, 육아 종성 병변 (hyperplastic, granulomatous lesions), 궤 양성 병변 (ulcerative lesions), 그리고 섬유화에 의한 협 착성군 (fibrostenotic group) 등 4가지 군으로 분류할 수 있다 ${ }^{12)}$. 이중 궤양성 병변이 가장 많다고 보고되어 있으 나 ${ }^{13)}$, 저자들의 경험으로는 적어도 한국에서는 궤양성 병 변은 극히 드문 것으로 생각되며 이는 아마도 기관지 결 핵에서 기관지 내시경을 시행하는 시점과 관련이 있는 것 으로 생각된다 ${ }^{14)}$. 기관 및 후두 결핵은 기관지 내시경상 비특이적 염증 및 궤양, 매독, 종양, lethal midline granuloma, Wegener 육아종증, sarcoidosis, 진균감 염 등의 여러 질환과 감별을 요한다. 조직생검은 조직 손 상으로 부종을 증가시켜 폐쇄증상을 악화시키거나 새로 운 감염의 통로로 작용할 수도 있고 출혈로 인해 혈행성 으로 혹은 기관지 강을 따라 병의 전파를 야기시키는 등 의 위험성으로 인해 신중히 고려해야 하며 조직검사로 얻 을 수 있는 정보보다 위험성이 더 크다고 한 보고들도 있 다 ${ }^{12,15,16)}$. Jenks ${ }^{2}$ 는 결핵으로 생각되지 않는 병변에서 만 조직 생검을 해야한다고 하였다. 그러나 최근에는 항 결핵제의 개발로 인하여 그 위험성은 거의 없다고 할 수 있다9).

기관 및 후두 결핵의 치료는 폐결핵의 치료법과 마찬 가지로 전반적인 신체 저항력의 향상과 함께 항결핵제를 투여해야 한다. 후두 결핵의 경우는 대개 투약 2 3주내 에 호전을 보여 후두 점막의 궤양과 부종이 가라앉게 된 다 ${ }^{10)}$. 그러나 항결핵제의 투여만으로는 후기 합병증인 반 흔성 협착의 예방이 만족스럽지 못하다. Nemir 등기이
기관지 결핵에서 스테로이드 병용 요법으로 후기 반흔성 협착의 예 방이 가능하다고 보고하였으며 Gerbeaux 등 ${ }^{18)}$ 도 기관지 결핵의 초기에 스테로이드를 투여하면 초기의 비특이성 염증 반응과 괴사를 억제하고, 다른 약제의 투 과성을 촉진시키며, 교원 조직의 반응도 억제하여 섬유 화로의 진행을 방지할 수 있다고 보고하였다. 이러한 치 료에도 불구하고 협착이 남는 경우가 있는데 병변 분절 이 짧을 때는 수술적 요법이 가능하지만 ${ }^{19)}$ 긴 경우는 수 술적요법이 불가능하여 기관지 내시경을 이용한 국소 요 법 및 Nd-YAG laser를 이용한 치료법이 시도되고 있 다 ${ }^{20,21)}$.

\section{결 론}

저자들은 서울대학교 병원에 호홉곤란을 주소로 입원 한 19 세 여자환자에서 급성 호흡부전으로 인하여 응급 기 관절개술을 요했던 후두 결핵에 동반된 상부 기관 결핵 을 경험하였기에 문헌고찰과 함께 보고하였다.

\section{REFERENCES}

1) Thompson Sir St. Clair: Tuberculosis of the larynx: Ten years experience in a sanatorium. HMSO, London.

2) Wathen CG, Kerr KM, Cowan DL, Douglas AC: Tuberculosis of the trachea. Tubercle 68:225-228, 1987

3) Bugher JC, Littig J, Culp J: Tuberculous tracheobronchitis Its pathogenesis. Am JM Sc 193:515, 1937

4) Jenks RS: Tuberculous tracheobronchitis. Am Rev Tuberc 41:692, 1940

5) Flance IJ, Wheeler PA: Postmortem incidence of tuberculous tracheobronchitis. Am Rev Tuberc 39: 633, 1939

6) Sweany HC, Behm H: Tuberculosis of the trachea and major bronchi. Dis of Chest 14:1, 1948

7) Auerbach O: Tuberculosis of the trachea and major bronchi. Am Rev Tuberc 60:604, 1949

8) Ormerod FC: Tuberculosis of the upper respiratory tract. Staples Press Ltd, London, 1939

9) Bailey CM, Windle-Taylor PC: Tuberculous laryngitis. Laryngoscope 91:93-100, 1981

10) Gertler R, et al: Tuberculous laryngitis-a one year harvest. J Laryngol Otol 99(11):1119-25, 1985 Nov 
11) Riley RL, Mills CC, O'Grady F, Sulten LU, Wittstadt F, Shirpuri DN. Am Rev Resp Dis 85:511-525, 1962

12) Samson PC, Barnwell J, Littig J, Brugher JC: Tuberculous tracheobronchitis. JAMA 108:1850, 1937

13) Wadsworth $W$, Arthur EH: The diagnosis and treatment of tuberculous tracheobronchitis. Am Rev Tuberc 315, 1937

14) 정희순, 한성구 : 기관지 결핵에 대한 내시경적 고찰 (미발표)

15) Barnwell JB, Littig J, Culp JE: Ulcerative tuberculous tracheobronchitis. Am Rev Tuberc 36:8, 1937

16) Samson PC: Diagnosis, treatment and prognosis in tuberculous tracheobronchitis. J Thoracic Surg 6: 561, 1937
17) Nemir BL, Cardona J, Vaziri F, Rosario T: Prednisone as an adjunct in the chemotherapy of lymph node-bronchial tuberculosis in childhood. A doubleblind study. Am Rev Resp Dis 75:402, 1967

18) Gerbeaux J, Baculard A, Couvreur J: Primary tuberculosis in childhood. Am J Dis Child 110:507, 1965

19) Mellem H, Boye NP, Arnkvaerin R, Fgeld NBj: Stenotic tuberculous tracheitis treated with resection and anastomosis. European Journal Respiratory Disease 68:224, 1986

20) Dumon JF, Cavaliere S, Milano S: The use of YAG laser in tracheobronchial diseases. Minerva Pneumol 21:44-6, 1982

21) McDougall JC, Cortese DA: Neodymium-YAG laser therapy of malignant airway obstruction. A preliminary report. Mayo Clin Proc 58(1):35-9, 1983 